\title{
A Climatology of the Tropical Tropopause Layer
}

\author{
A. GETTELMAN \\ National Center for Atmospheric Research, Boulder, CO, USA \\ and \\ P.M. de F. FORSTER \\ Department of Meteorology, University of Reading, Reading, UK
}

(Manuscript received 4 June 2001, in revised form 17 September 2001)

\begin{abstract}
The tropical tropopause layer (TTL) is a transition region between the troposphere and the stratosphere. In this study the vertical extent of the TTL is diagnosed from radiosonde and ozonesonde profiles in the tropics and a climatology of this layer is presented. The radiative balance in the TTL is also characterized. The TTL is locally defined as extending from the level of the lapse rate minimum at 10 $12 \mathrm{~km}$ to the cold point tropopause (CPT) at $16-17 \mathrm{~km}$. The minimum in lapse rate represents the level of maximum convective impact on upper tropospheric temperatures, which is found to closely correspond to a minimum in ozone. Variations in this level are correlated with convective activity as measured by satellite brightness temperatures and Outgoing Longwave Radiation (OLR). At the cold point, the TTL height is nearly uniform throughout the tropics, and has a pronounced annual cycle. There are regional variations in the altitude of the lower boundary of the TTL. Interannual variations of the TTL result from changes in the large scale organization of convective activity, such as from the El-Niño Southern Oscillation (ENSO). Over the last 40 years, records indicate an increase $(200-400 \mathrm{~m})$ in the height of both the cold point tropopause and the level of minimum lapse rate. To better understand vertical transport in the TTL, the clear sky radiative heating rate is diagnosed using a sophisticated radiative transfer scheme. The level of zero radiative heating occurs roughly $1 \mathrm{~km}$ below the CPT, implying that convection needs to loft air $4-5 \mathrm{~km}$ above the base of the TTL if the air is to eventually enter the stratosphere.
\end{abstract}

\section{Introduction}

The tropical tropopause is not a material surface. It has been recognized for some time that a single valued definition of the tropopause, designed for the extratropics, may not be appropriate in the tropics. It is perhaps better to think of the the tropical tropopause layer (TTL) as a transition layer between the con-

Corresponding author: A. Gettelman, National Center for Atmospheric Research, Box 3000, Boulder, CO, 80307-3000, USA.

E-mail: andrew@ucar.edu

(C) 2002, Meteorological Society of Japan vectively dominated tropical troposphere and the radiatively controlled stratosphere.

The TTL is important as the source region for much of the air entering the stratosphere (Holton et al. 1995). As discussed first by Brewer (1949), the boundary condition for stratospheric water vapor is likely set in this region. The interaction of convection, the stratospheric wavedriven circulation and horizontal exchange with the midlatitude lower stratosphere gov-

This manuscript was prepared with modified AGU's IATEX macros v3.0, with the extension package 'AGU'++' by P.W. Daly, version $1.5 \mathrm{e}$ from 1997/11/18, modified for AMS journals. 
erns the transport of ozone, aerosols and other short lived chemical species into the stratosphere. The relative roles of these processes in the TTL is unclear, and the boundaries of the TTL are defined qualitatively differently by different authors (see below). In this work, we set out a definition for the vertical boundaries of the TTL based on simple theoretical arguments and observations. The definition is not the only one possible (see below), but allows us to examine the upper and lower boundaries of the TTL together using radiosonde and ozonesonde data. We use this definition to develop a climatology for the TTL, and then investigate the radiatively driven vertical motion in the TTL. We conclude by refining the conceptual picture of the TTL.

The concept of a tropical tropopause layer rather than a tropopause surface has been recently discussed by Highwood and Hoskins (1998) in the context of the large scale tropical circulation, extending from the main convective outflow to the cold point. Sherwood and Dessler (2001) have defined the TTL as the region where convection overshoots its level of neutral buoyancy, extending from about $150 \mathrm{hPa}$ to $50 \mathrm{hPa}$. Folkins et al. (1999) has noted a change in the stability and increase in ozone at about $14 \mathrm{~km}$. Vömel et al. (2002) went on to note there were important spatial and temporal variations in this structure, and that the TTL lower boundary can be defined by a local minimum in relative humidity. Thuburn and Craig (2002) have recently explored the thermodynamic basis for the layer and defined it as a region where radiation is more important than convection, but convection is more important than chemical production of ozone.

However, the concept of a tropopause layer is not new. There is a long tradition of defining multiple tropopause levels in soundings by successive changes in lapse rate toward increasing stability. In the extratropics and sub tropics, multiple tropopause structures go at least back to Bjerknes and Palmén (1937), who called the region between these multiple tropopauses the 'sub-stratosphere'. Willett (1944) also defined the tropopause as a layer rather than a surface, extending well into the subtropics. Multiple tropopause structures were discussed extensively by Kochanski (1955), who noted the extension of the extratropical tropopause to the equator as a 'secondary tropopause' at 10$12 \mathrm{~km}$. This concept was picked up on again by Palmén and Newton (1969), and by Shapiro (1980). Later, Atticks and Robinson (1983) noted from looking at tropical temperature soundings that the tropical tropopause was really a 'transition region' between the stratosphere and the troposphere.

In this work we define the tropical tropopause layer in more detail. We make a case that the level of minimum temperature or potential temperature lapse rate is a good marker for the maximum influence of convection on the temperature profile and hence the base of the TTL. The upper boundary of the TTL is well characterized by the cold point. We introduce the data in Section 2. We develop and justify our definition of the TTL in Section 3. Using this definition we then present a climatology of the TTL in Section 4. To better understand vertical transport in the TTL, clear sky radiative heating rates are calculated using a detailed radiative code in Section 5. Discussion and the implications of this study are found in Section 6.

\section{Data}

For high vertical resolution information on the tropopause layer, we use vertical sounding information from radiosondes and ozonesondes. These data have the advantage of relatively high vertical resolution and fairly high precision. In addition, there are sufficient observations to capture many scales of variability and to minimize random errors. Radiosonde observations are drawn from the standard upper air Global Telecommunications System (GTS) network, collected by the National Centers for Environmental Prediction (NCEP) for 1989-1999. To supplement this data (which may have temporal gaps in individual station records), we also use data from a small subset of stations in the Comprehensive Aerological Research Data Set (CARDS) radiosonde archive (Eskridge et al. 1995) over a longer time period (1958-1997).

In addition to these records, we use highvertical resolution (50-100 m) ozonesonde data from the SHADOZ ozonesonde archive (Thompson and Witte 1999). This data set provides several hundred soundings of temperature and ozone from 10 stations in the southern hemisphere tropics on an operational basis since 
1998. This data will be supplemented with two independent proxies of convective activity; satellite brightness temperatures and daily averaged Outgoing Longwave Radiation (OLR). Satellite brightness temperatures are derived from infrared radiances at high space and time resolution as described by Salby et al. (1991), and are available only for a few years. Daily averaged OLR is available for a much longer time record. OLR is derived from the same infrared radiances, interpolated by the $\mathrm{Na}$ tional Oceanic and Atmospheric Administration (NOAA), and provided by the NOAA Climate Diagnostics Center, Boulder, Colorado (http://www.cdc.noaa.gov/).

This study uses linear correlation analysis. Significance of linear correlations, unless otherwise noted, is reported assuming a 95\% confidence level and a 2-sided T-test with appropriate degrees of freedom (Santer et al. 2000), which for the trend analyses is typically one degree of freedom per year.

\section{Definition of the TTL}

The transition between the stratosphere and troposphere occurs in the tropopause layer, as the influence of convection tails off with height. The theoretical basis for the TTL 'transition layer' is illustrated in Fig. 1. Figure 1a illustrates several different temperature profiles representative of stratospheric and tropospheric stability regimes. A radiative equilibrium profile taken from Manabe and Wetherald (1967) represents the stratospheric regime. The model uses profiles of ozone from observations and fixed relative humidity and carbon dioxide in the vertical. It is broadly but not specifically applicable to the tropics. The tropospheric regime is defined as the region in which the atmosphere is in recent contact with with the boundary layer through convection (rapid vertical motion). A convective equilibrium profile is represented by a profile of constant saturated equivalent potential temperature $\left(d \theta_{e s} / d z=0\right)$. In Figure 1 the profile is plotted for $\theta_{e s}=360$, and does not necessarily represent the same energy balance as the radiative equilibrium curve. Also plotted in Fig. 1 are an isothermal profile $(d T / d z=0)$ and an adiabatic profile $\left(d T / d z=\Gamma_{d}\right.$, the dry adiabatic lapse rate). Note that the combination of a convective equilibrium profile from the surface to the region of

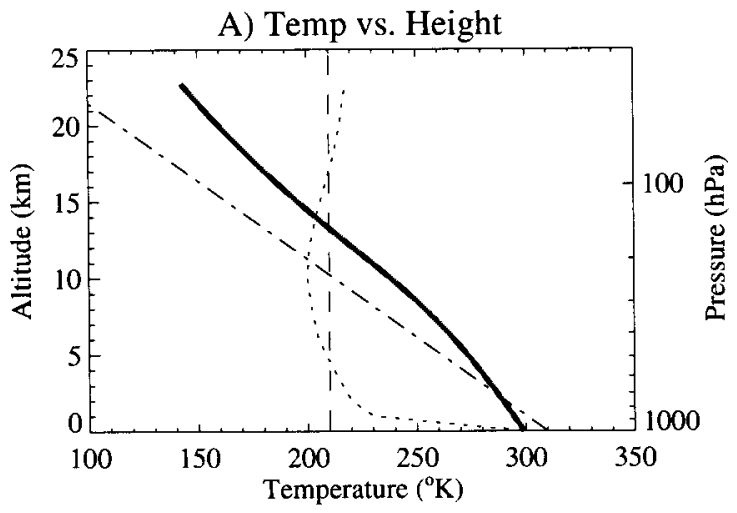

B) $\theta$ vs. Height

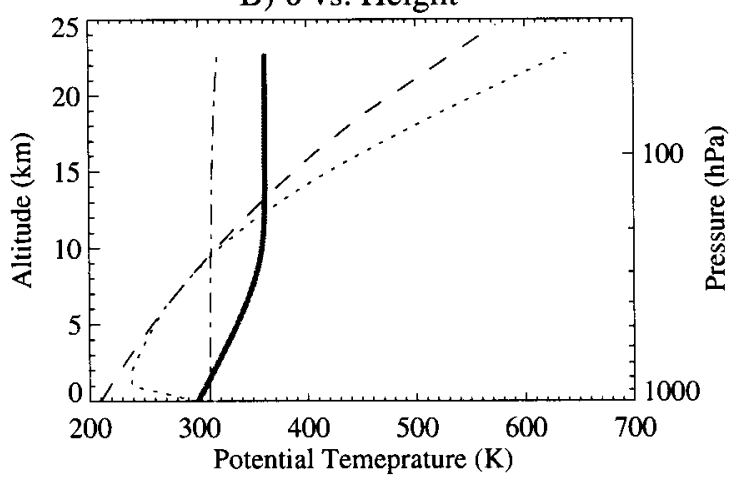

C) $\theta$ Lapse Rate vs. Height

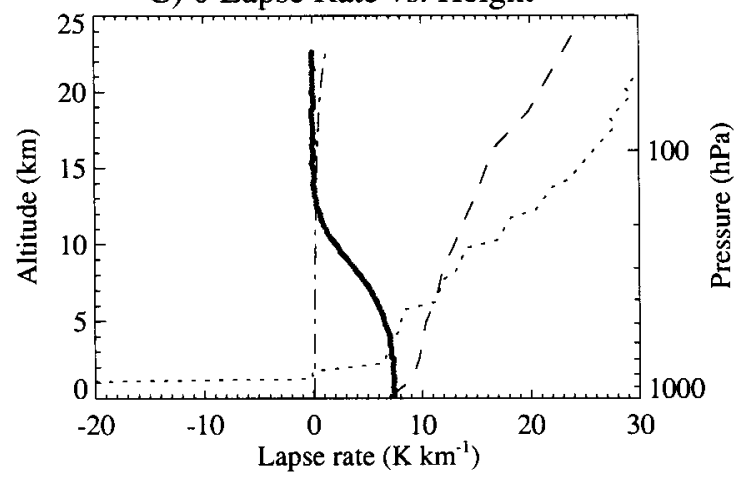

Fig. 1. Theoretical profiles of A) temperature, B) potential temperature $(\theta)$ and C) potential temperature lapse rate. Four lines are shown. The solid line is convective equilibrium or constant saturated equivalent potential temperature $\left(d \theta_{e s} / d z=0\right)$. The dotted line is radiative equilibrium (Manabe and Wetherald 1967). The dashed line is isothermal $(d T / d z=0)$. The dash-dot line is a dry adiabat, $\left(d T / d z=\Gamma_{d}\right)$. 


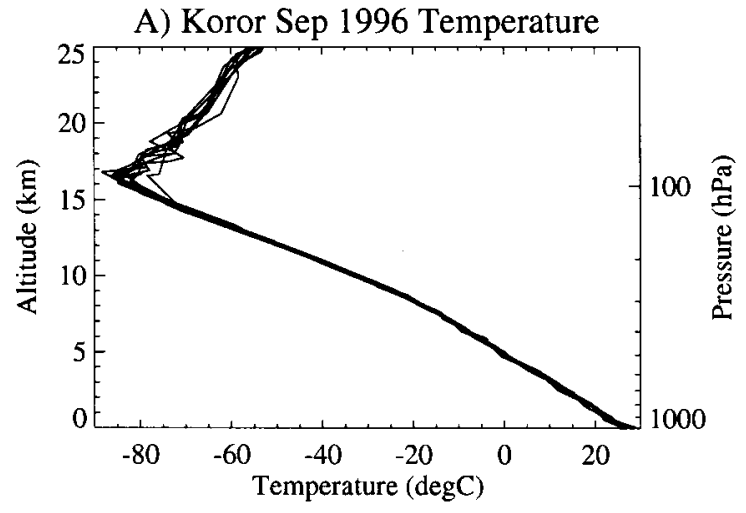

B) Koror $\theta$
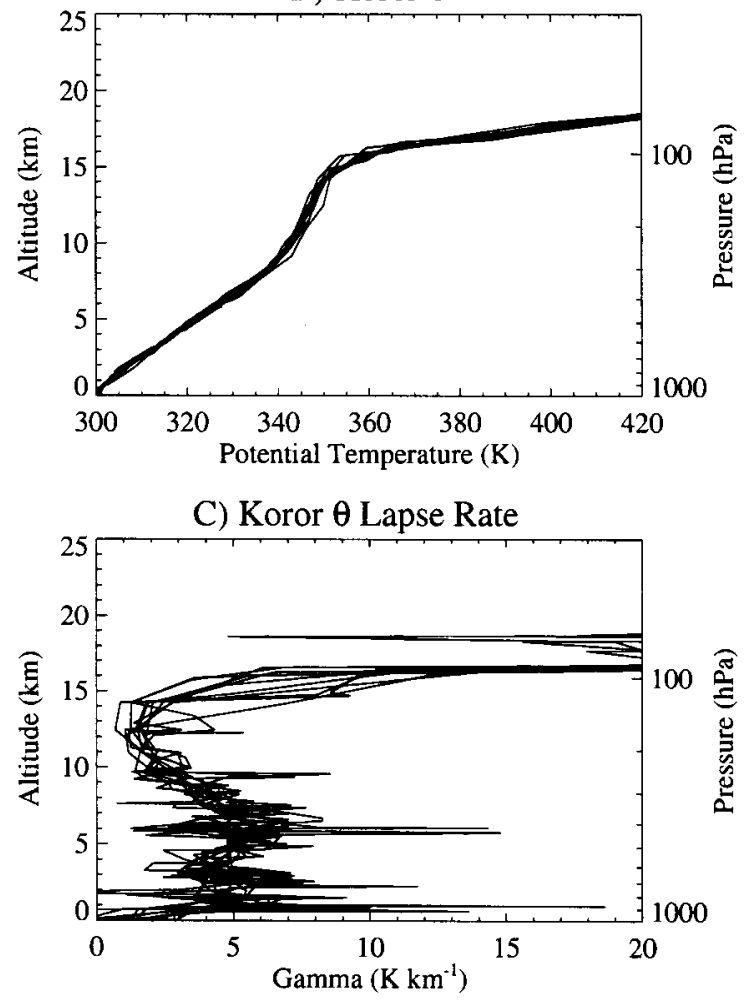

Fig. 2. Radiosonde profiles at Koror $\left(7.3^{\circ} \mathrm{N}, 134.5^{\circ} \mathrm{E}\right)$ in September 1996 for A) temperature, B) potential temperature $(\theta)$ and $\mathbf{C}$ ) potential temperature lapse rate. 39 soundings plotted.

the tropopause and a radiative equilibrium profile above this in the stratosphere (Fig. 1a) looks very much like an atmospheric sounding in the tropical Western Pacific (Fig. 2a).

It is much easier to examine the thermal structure of the TTL by looking at the soundings in terms of potential temperature $(\theta)$. The potential temperature approaches a constant (dry adiabatic) value with height as all the water is removed (Fig. 1b). Again, the combination of convective equilibrium and radiative equilibrium resembles actual tropical soundings (Fig. 2b). At tropopause levels (15 km) and above, the potential temperature lapse rate goes to zero in a convective profile, but in the radiative profile it increases rapidly (Fig. 1c). The difference in lapse rate signature provides a clear transition between the stability regimes which can be precisely located. The lapse rate minimum (LRM) in the upper troposphere marks the level where radiation begins to influence the temperature an it departs from a saturated moist adiabat. Some convection does continue much higher than this level. The altitude of the lapse rate minimum for the soundings in Fig. 2 is between $10-14 \mathrm{~km}$, significantly below the cold point tropopause (CPT) at $16 \mathrm{~km}$ (Fig. 2c). The LRM is where the stability begins to change, and we will use this to define the bottom boundary of the tropical tropopause layer (TTL).

We define the top boundary of the TTL from the point where the vertical gradient of temperature becomes positive, which happens at the cold point tropopause (CPT). Above the CPT lies the stratospheric inversion, where convective motions do not significantly influence the stability. The cold point tropopause is located just above $100 \mathrm{hPa}$ in the soundings in Fig. 2a. The CPT is nearly coincident with the level of minimum saturation vapor mixing ratio, which is critical for water vapor entering the stratosphere, and 1-2 km below the climatological hygropause (water vapor minimumKley et al. 1979). A small fraction of the time, convection penetrates above the cold point in isolated locations and seasons (Gettelman et al. 2002).

The LRM level is coincident with the level of the minimum in ozone mixing ratio in the ozonesondes in the SHADOZ archive. Figure 3 compares the altitude of the LRM compared to the altitude of the minimum in upper tropospheric ozone, from ozonesondes launched over Watukosek, Indonesia $\left(7^{\circ} \mathrm{S}, 112^{\circ} \mathrm{E}\right)$. These soundings have a vertical resolution of 50$100 \mathrm{~m}$. Layered structures complicate finding the exact minimum by perhaps $100-200 \mathrm{~m}$. Low pass filtered results to remove small verti- 


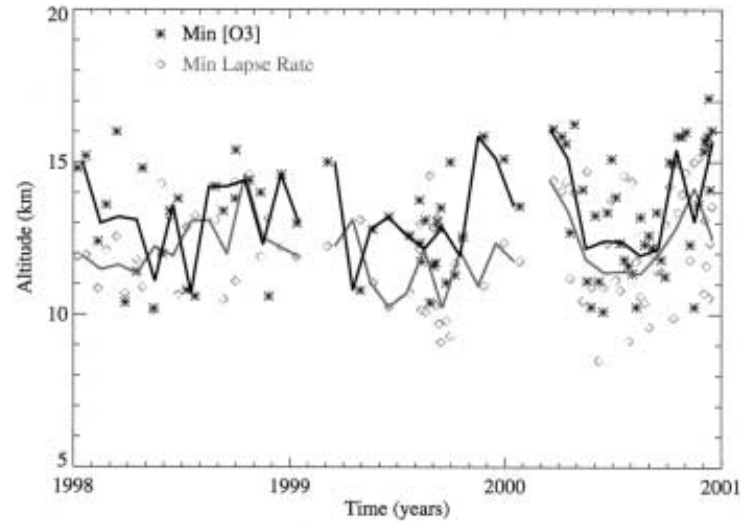

Fig. 3. Altitude of upper tropospheric ozone minima (asterix and solid black line) and the altitude of the lapse rate minimum or LRM (diamonds and solid gray line) at Watukosek, Indonesia on the island of Java $\left(7^{\circ} \mathrm{S}, 112^{\circ} \mathrm{E}\right)$. Symbols represent individual soundings and solid lines are monthly means of the data.

cal scale structures yield the same general altitude of the ozone minimum in all cases examined. In general, the ozone minimum in the upper troposphere is just above the LRM. Over Indonesia this altitude is about $10-14 \mathrm{~km}$. Variability of the monthly averages of the heights of these quantities (solid lines in the figure) is similar over an annual cycle. These results are typical of other SHADOZ sites with more than 50 soundings over 1998-2001. The variation of the ozone minimum in the upper troposphere, just above the LRM, is consistent with a convective influence on ozone at this level, possibly transport of low ozone air from the surface (most of the SHADOZ stations are in remote sites with low surface ozone).

Observations of convection from satellites further demonstrate that the LRM is associated with convective activity, at least on a average basis. Using a subset of the sounding data for one year at Koror, satellite brightness temperatures within approximately $1^{\circ}$ of latitude or longitude and 3 hours in time are converted to altitude based on sounding temperatures to generate an approximate cloud height. A linear correlation of this cloud height with the altitude of the LRM (0.3) is significant at the $95 \%$ level. Furthermore, scatterplots in- dicate that convection is rarely found significantly above the LRM. The LRM is approximately the level the convection reaches in a location or nearby region, (though the LRM may be well above the level of clouds on any given day). The LRM is thus associated with convection, but the effects of convection on the LRM are distributed over time and space.

In addition, the LRM altitude can be correlated with observations of local convection using daily mean values of OLR over a longer record. Because OLR observations are daily averages over hundreds of kilometers, and because the Stefan-Boltzmann conversion from OLR to brightness temperature is non-linear, the brightness temperatures calculated from average OLR observations do not directly correspond to the temperature at the altitude of the LRM. However, OLR variability should correspond to variations in the LRM altitude. Analysis of the correlations between OLR and LRM altitude using 21 stations from the CARDS radiosonde archive throughout the tropics for almost 20 years (1979-1997) does indicate significant correlations. For monthly averages, 19 of 21 radiosonde stations had statistically significant correlations (95\% confidence level). Over half the stations had correlations of higher than -0.5 (decreasing OLR is associated with a higher altitude of lapse rate minimum). For individual sounding launches, 18 of 21 stations had significant correlations between OLR and the height of the lapse rate minimum. The base of the TTL has also been marked by a minimum in relative humidity over ice (RHI) at $12-15 \mathrm{~km}$ in soundings by Vömel et al. (2001), which is a similar level to the ozone minimum or lapse rate minimum. Unfortunately, the limited quality of radiosonde humidity measurements make this an impractical level for developing a climatology, or for comparison with the minimum lapse rate.

The correlations with convection observed from satellites, and with ozone (Fig. 3) indicate that the LRM height is coupled to convection. Several other sets of observations confirm the relationship between the LRM and convection. The average potential temperature of the LRM is near $345-350 \mathrm{~K}$, in agreement with the peak in the distribution of surface equivalent potential temperature (Folkins 2002). The equiva- 
lent potential temperature $\left(\theta_{e}\right)$ is the potential temperature $(\theta)$ plus the latent heat releasable from the water vapor in a parcel, or the maximum $\theta$ a parcel could reach if lifted from the surface. The level of the LRM at $10-14 \mathrm{~km}$ $(250-150 \mathrm{hPa})$ is also the level of main poleward flow in the Hadley circulation (Peixoto and Oort 1992), and the level of maximum divergence of the horizontal wind in the tropical troposphere. In addition, histograms of cloud brightness temperatures show a local maximum in the coverage of cold cloud at about this level (Gettelman et al. 2002). Along with the theoretical analysis of Fig. 1, these data indicate that the LRM is closely associated with the maximum impact of convection on a temperature profile or the main convective outflow level. Having established this definition of the TTL, we can examine a climatology of the TTL using a broad radiosonde network.

\section{Climatology}

Using the observations from the radiosonde network, a climatology of the tropical tropopause layer can be derived. As the top of the layer we use the cold point tropopause, and as a lower boundary, we adopt the altitude of the lapse rate minimum, diagnosed using potential temperature, as discussed in section 3 . We will present most of the analyses in isentropic coordinates to highlight the diabatic motions necessary to move parcels into and through the TTL. For reference, the $350 \mathrm{~K}$ isentropic surface is at $\sim 12 \mathrm{~km}$, and the $330 \mathrm{~K}$ isentropic surface is at $\sim 9 \mathrm{~km}$.

The seasonal variation of the TTL is illustrated in Fig. 4 for two stations in the tropical Western Pacific. Koror is located north of the equator (7.3 N, 134.5 E), and Darwin south of the equator $(12.4 \mathrm{~S}, 130.9 \mathrm{E})$. The figure is constructed from sounding records over $\sim 20$ years from 1979-1997, with approximately 800 soundings in each monthly average. Standard deviations $(\sigma)$ are noted for each data set. These deviations do not change significantly between stations or month to month. Both these stations have an annual cycle in the height of the CPT which is nearly identical. The CPT is a maximum in January-March, and a minimum in June-August. This is consistent with observations by Seidel et al. (2001) and with the stratospheric wave driving, which

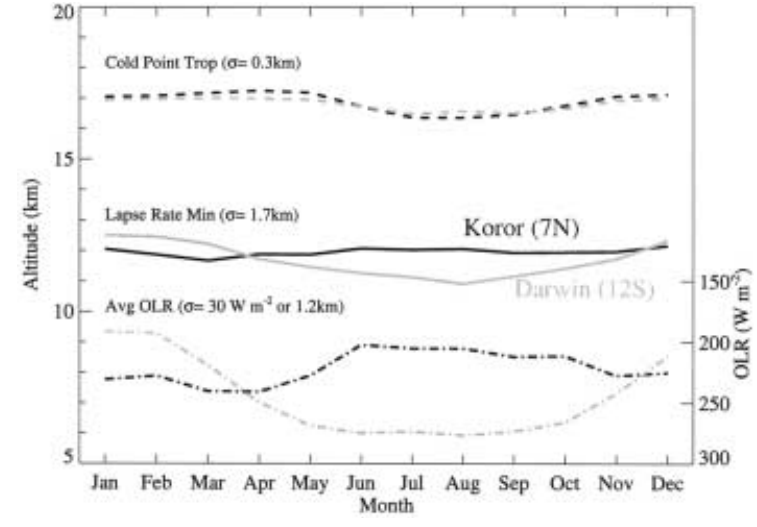

Fig. 4. Monthly mean tropical tropopause layer depth and convective activity for Koror (black lines) and Darwin (gray lines). Dashed lines indicate the altitude of the cold point tropopause (CPT), solid lines indicate the altitude of the lapse rate minimum (LRM), both in kilometers (left scale). The dash-dot lines indicate the average Outgoing Longwave Radiation (OLR) in $\mathrm{W} \mathrm{m}^{-2}$ (right scale). Standard deviations $(\sigma)$ are indicated next to each legend.

lifts and cools the tropopause during northern hemisphere winter (Holton et al. 1995).

The annual cycle of the LRM height is different between these stations (Fig. 4), with a more pronounced annual cycle at Darwin. At both stations the altitude of the LRM averages 11-12 km. The altitude of the LRM at Koror has a weak maximum $(12 \mathrm{~km})$ in June-August, when the LRM altitude at Darwin $(11 \mathrm{~km})$ is at a minimum. Also illustrated in Fig. 4 is the monthly averaged OLR at the station locations. The seasonal variation of the LRM corresponds to the variations in OLR at each station. Correlations of monthly average minimum lapse rate height with monthly average OLR are strong ( -0.97 for Darwin and -0.57 for Koror), and significant at the $95 \%$ level. Correlations for individual soundings of the LRM altitude with daily mean OLR over 1979-1997 (-0.32 for Darwin and -0.14 for Koror) are also significant at the 95\% level (assuming one degree of freedom each month). These correlations are further evidence that the LRM is associated with convection. As with the minimum ozone level, the effect of convection on the LRM level appears to be stronger averaged over time. The 
A) Jan min lapse rate $\theta(\mathrm{K})$

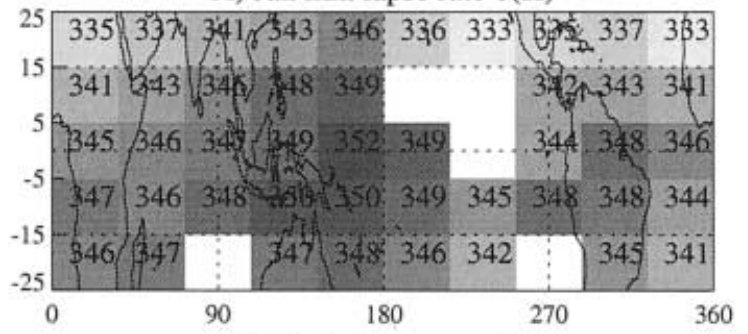

C) Jul min lapse rate $\theta(\mathrm{K})$

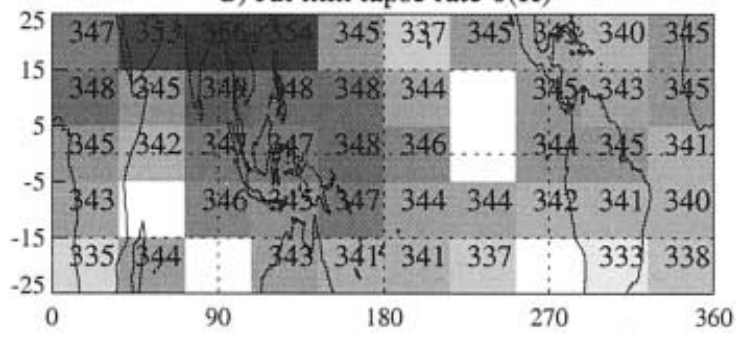

B) Apr min lapse rate $\theta(\mathrm{K})$

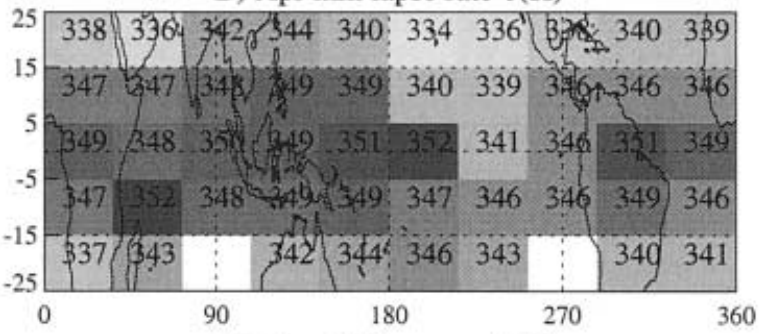

D) Oct min lapse rate $\theta(\mathrm{K})$

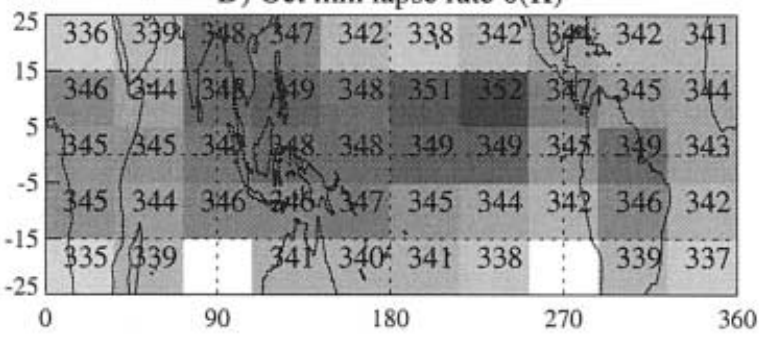

Fig. 5. Monthly mean lapse rate minima potential temperature $(\theta)$ from GTS sounding network for A) January, B) April, C) July and D) October. Darker shading indicates higher potential temperature, whose values (in K) are labeled. Data is taken from from 1989-1999, and regions with insufficient data are left blank.

altitude or temperature of the cold point in individual soundings is not significantly correlated with OLR $(-0.04$ for Darwin and -0.06 for Koror).

The complete Global Telecommunications System (GTS) sounding set can be used to generate maps of the seasonal cycle of lapse rate altitudes. In Fig. 5 we illustrate the seasonal cycle of the LRM height, in isentropic coordinates, based on 11 years of data from 19891999. There are roughly 200 soundings per day between $\pm 30^{\circ}$ during this period. In January (Fig. 5a), maximum potential temperatures of the LRM are located in the Western Pacific (352 K) and over South America (348 K). In April (Fig. 5b), these maxima have shifted slightly, to the Central Pacific (352 K) and over South America (351 K). In July (Fig. 5c), maximum potential temperatures of the LRM are found over India (356 K), associated with the Indian monsoon convection. Finally, in October (Fig. 5d), maxima are to be found in the Intertropical Convergence Zone (ITCZ) north of the equator $(352 \mathrm{~K})$. The altitude of these LRM values ranges from $10-13 \mathrm{~km}$. The seasonal pattern of the altitude of the LRM in Fig. 5 is strongly coupled to local convective activity.
See Gettelman et al. (2001) for maps of deep convective activity. The relationship is consistent with the correlations with brightness temperature and OLR, presented in Section 3 .

These seasonal patterns result in an annual mean distribution with geographical differences in the potential temperature of the LRM (Fig. 6). Maximum potential temperatures are found in the Western Pacific $(350 \mathrm{~K})$, and over tropical South America (348 K), and Southern Africa ( $347 \mathrm{~K})$. In the annual mean, there are differences of $7 \mathrm{~K}$ in potential temperature. In altitude, this difference is around a kilometer $(12 \mathrm{~km}$ in the Western Pacific to $11 \mathrm{~km}$ in the eastern Pacific or Atlantic). In general the potential temperature of the LRM is lower in the subtropics (from $15-30^{\circ}$ latitude).

Seidel et al. (2001) have used roughly 80 radiosonde stations in the CARDS network to examine the variations of the cold point tropopause. Seidel et al. (2001) found that the maximum height of the cold point tropopause was in January-March, and the minimum height was in July-September, similar to Fig. 4. The potential temperature of the cold point has a similar cycle, but varying by only $2-3 \mathrm{~K}$. 


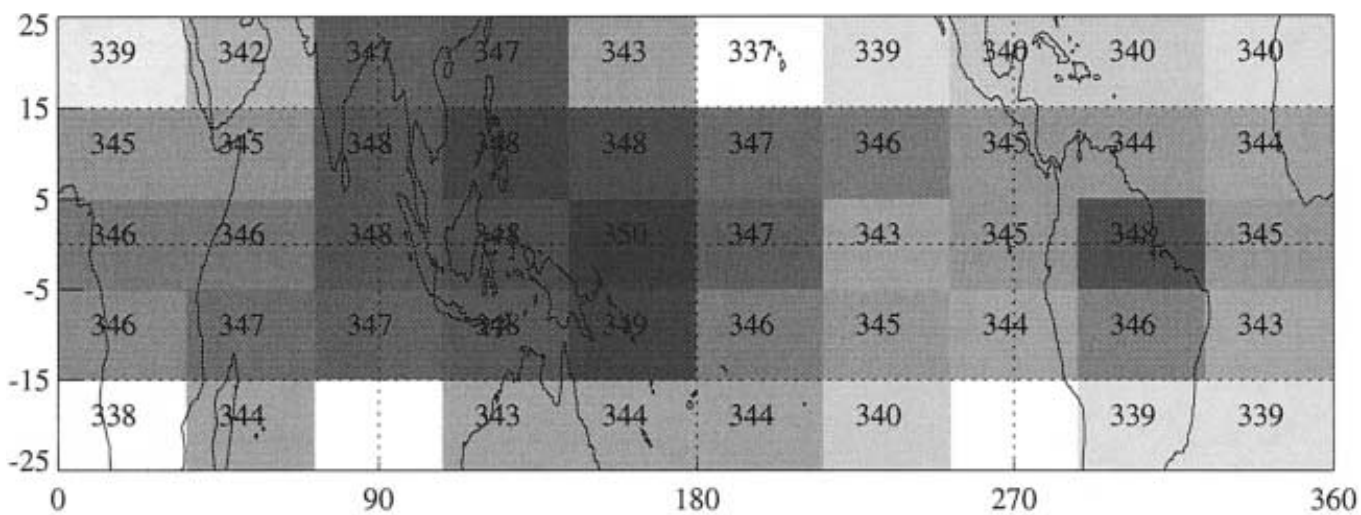

Fig. 6. Annual mean lapse rate minima potential temperature $(\theta)$ from GTS sounding network. Darker shading is higher potential temperature, with value (in K) labeled. Data is taken from from 1989-1999, and regions with insufficient data are left blank.

Seidel et al. (2001) also found that the cold point was several hundred meters lower and $5 \mathrm{~K}$ (potential temperature) cooler over the Western Pacific. The TTL in the Western Pacific thus has a higher base (Fig. 6) and a lower top than at other longitudes.

Figure 7 illustrates the interannual variability of the CPT and the LRM for a station in the Western Pacific (Koror-7.3 N, 134.5 E) and in the Central Pacific (Pago Pago-14.3 S,
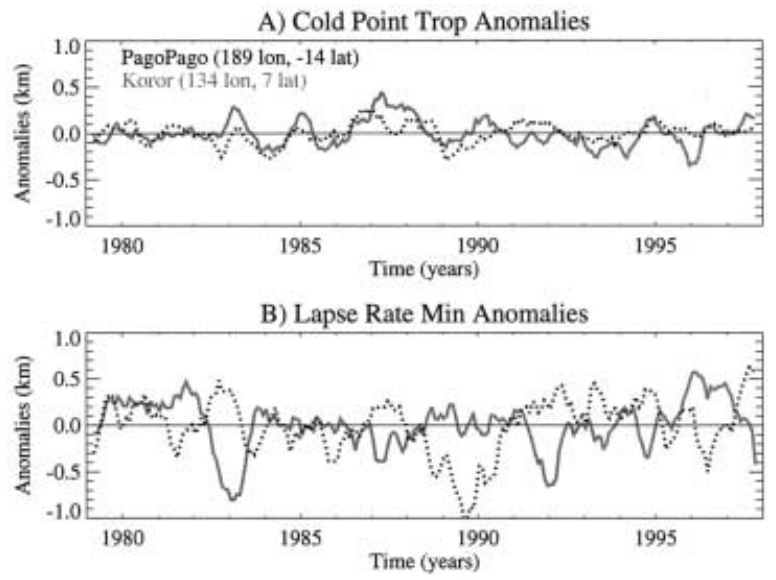

Fig. 7. Monthly mean anomalies of A) cold point tropopause (CPT) altitude and B) Altitude of lapse rate minimum (LRM). Koror (solid grey line) and Pago Pago (dotted black line). Anomalies are calculated from monthly means and smoothed with a 5 month running mean.
$170.7 \mathrm{~W}$ ). The monthly anomalies (smoothed with a 5 month running mean) in cold point tropopause height between the stations (Fig. 7a) are correlated (0.35). However, the anomalies in minimum lapse rate (Fig. 7b) are weakly anti-correlated (-0.17), and strongly coupled with cycles of the El Niño Southern Oscillation (ENSO). During the strong ENSO warm event (El Niño) in 1982-3, the LRM height fell at Koror and rose at Pago Pago, consistent with reduced convection in the Western Pacific and enhanced convection in the Central Pacific. Figure 7 also shows the beginning of similar behavior in late 1997, associated with the recent strong El Niño event. The full event is not resolved by this plot, which stops in late 1997 . Conversely, during the strong ENSO cold event (La Niña) in 1989-1990, the altitude of the LRM fell over Pago Pago.

Another way of examining ENSO variability is to use the larger radiosonde station network to look at differences between the warm and cold phases of ENSO. Figure 8 presents maps for January 1998 (Fig. 8a, an ENSO warm event) and January 1999 (Fig. 8b, an ENSO cold event). The altitude of the LRM moves to higher potential temperatures associated with increases in convection in the Central Pacific during January 1998 and in the Western Pacific during January 1999.

Finally, the long records available at select radiosonde stations allow us to calculate long term trends. For this calculation we use a subset of stations from the CARDS network with 
A) Min lapse rate $\theta(\mathrm{K}) \mathrm{Jan} 1998$

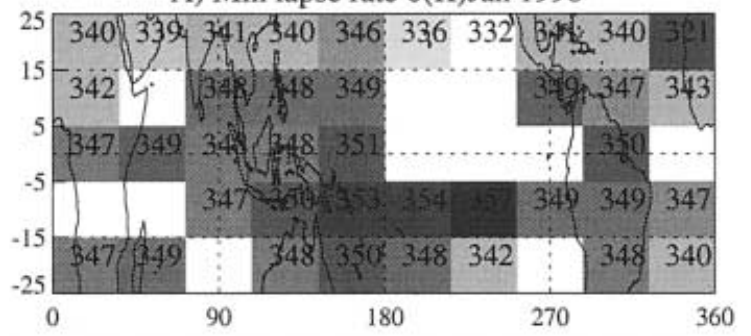

B) Min lapse rate $\theta(\mathrm{K}) \mathrm{Jan} 1999$

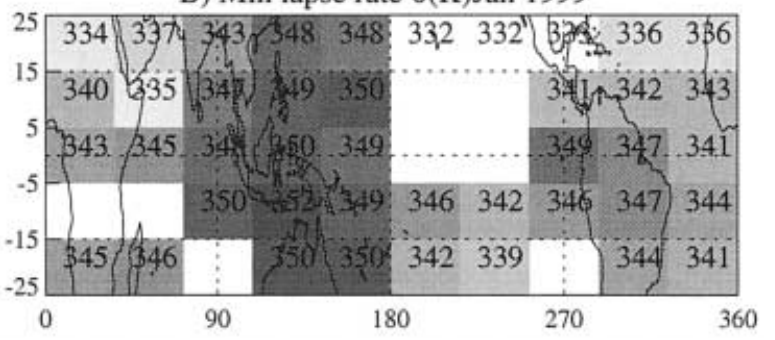

Fig. 8. Minimum lapse rate potential temperature ( $\theta$, in $\mathrm{K})$ from GTS soundings averaged for A) January 1998 and B) January 1999. Blank regions have insufficient data.

continuous records of at least 20 years. Annual averages are used to calculate a linear trend and whether it is significantly different from zero. Most of the records are 40 years long, spanning 1958-1997. The CPT height (Fig. 9a) is increasing at all but 2 of 16 stations with consistent records, and at all 9 stations with statistically significant (95\% level) trends. Not all the stations examined had consistent records over the last 20 years. Seidel et al. (2001) also reported increases in CPT height using a similar network. Trends in the potential temperature $(\theta)$ of the CPT have also been calculated, and on average these are close to zero, consistent with Seidel et al. (2001). However, slight increases of $0.5 \mathrm{~K} \mathrm{decade^{-1 }}$ are found in the Western and Central Pacific, while decrease in CPT $\theta$ averaging $2 \mathrm{~K}$ decade $^{-1}$ are found between Africa and South America. The height of the LRM is also generally increasing (Fig. 9b), though only 6 stations show statistically significant trends. These trends are a few hundred meters over the last 40 years. Trends in LRM $\theta$ are slightly positive throughout the tropics $\left(0.4 \mathrm{~K} \mathrm{decade}^{-1}\right)$. Outside of the Pacific, these trends to not appear to be significantly correlated with ENSO events.

\section{Radiative view}

In order to get a complete picture of vertical motion in the TTL, it is important to understand not just convection, but the background radiative heating and cooling of air subsequent to outflow in convection. In the troposphere there is radiative cooling by water vapor and air in clear sky regions subsides. But as the water vapor decreases with height its cooling effect will be reduced. At some altitude the clear sky heating rate will become positive due to heating by ozone. This level of zero clear sky radiative heating $\left(Q_{\text {clear }}=0\right)$ is important, because air detraining from convection in a region where $Q_{\text {clear }}<0$ will tend to sink back into the troposphere. Only above this level $\left(Q_{\text {clear }}>0\right)$ will air tend to rise into the stratosphere. Since convection brings into the TTL higher moisture and lower ozone, it has an important influence on the level of $Q_{\text {clear }}=0$.

We use a detailed radiative transfer code (Forster and Shine 1997) to estimate the level at which the clear sky radiative heating changes from negative (cooling and sinking motion) to positive (heating and upward motion). The radiation scheme is a 4 stream Discrete-Ordinate Method at $5 \mathrm{~nm}$ resolution in the solar and a $10 \mathrm{~cm}^{-1}$ narrow-band code in the thermal infrared. The model uses climatological profiles of temperature from European Center for Medium range Weather Forecasts (ECMWF) analyses (1980-1991). The ozone climatology is based on observations from ozonesondes merged with satellite instruments, including; the Total Ozone Mapping Spectrometer (TOMS), Solar Backscatter Ultraviolet (SBUV) and Stratospheric Aerosol and Gas Experiment (SAGE) instruments. The water vapor climatology is based on ECMWF analyses below $300 \mathrm{hPa}$ and observations from the satellite based Halogen Occultation Experiment (HALOE) and SAGE instruments above $300 \mathrm{hPa}$. See Christidis et al. (1997) for further details.

Using the detailed radiative transfer code and these monthly mean climatologies, we cal- 
A) CPT height trends $\left(\mathrm{m} \mathrm{yr}^{-1}\right)$

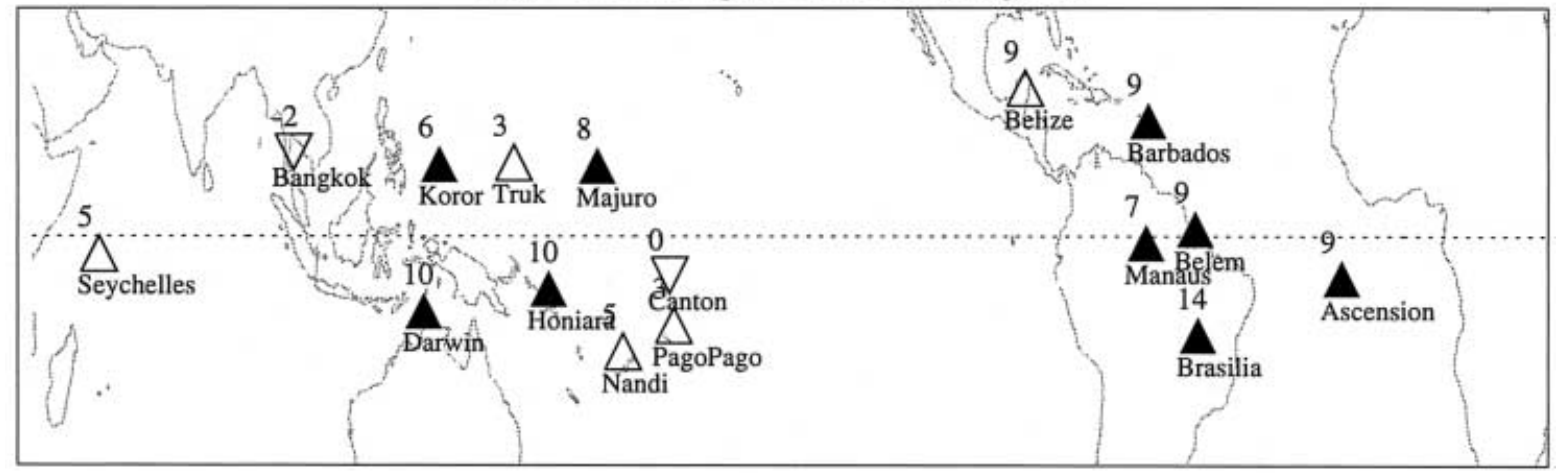

B) $\Gamma$ Min height trends $\left(\mathrm{m} \mathrm{yr}^{-1}\right)$

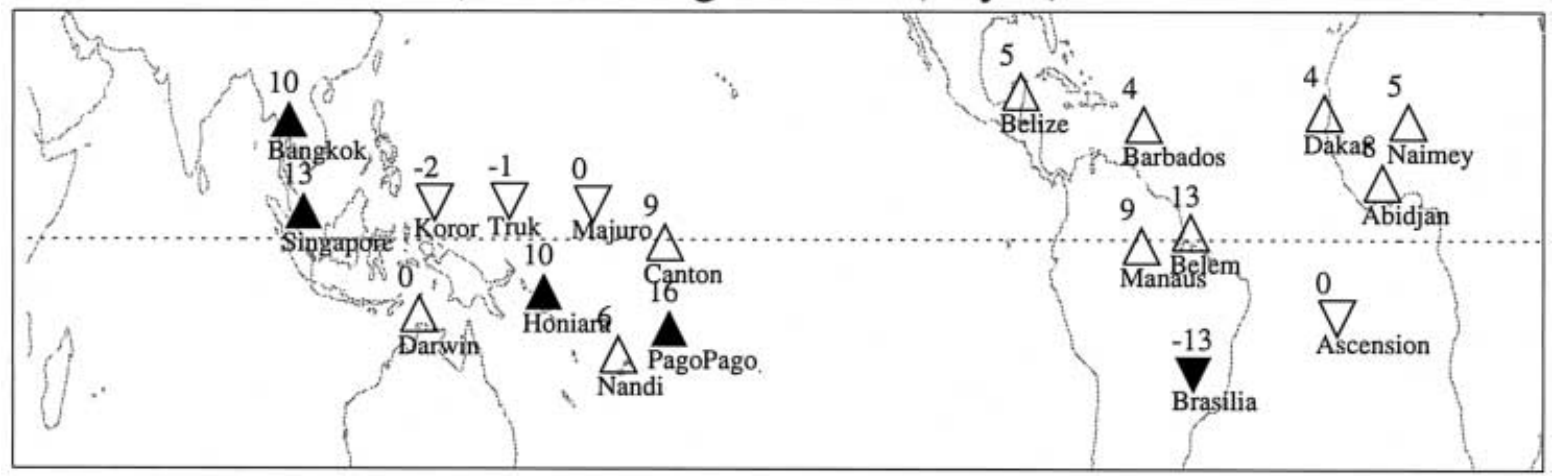

Fig. 9. Trends in height of A) cold point tropopause (CPT) and B) Lapse rate minimum (LRM) from CARDS radiosonde stations. Direction of triangle indicates direction of trend (up or down) with the name of station below and the trend (in $\mathrm{m} \mathrm{yr}^{-1}$ ) above. Solid triangles indicate trends which are statistically different from zero using a $95 \%$ confidence interval.

culate the level $Q_{\text {clear }}=0$ and compare it with the cold point tropopause. Figure 10 illustrates the tropical mean level of $Q_{\text {clear }}=0$ over the course of the year and the CPT tropopause from the climatology used to calculate the heating. Note that the climatological CPT derived from ECMWF analyses is about $200 \mathrm{~m}$ higher than observed by radiosondes (Seidel et al. 2001). The level of $Q_{\text {clear }}=0$ has only a small annual cycle, and is located about a kilometer below the tropopause. Zonally, $Q_{\text {clear }}=0$ is several hundred meters lower and the CPT several hundred meters higher in the Western Pacific throughout the year. The level of $Q_{\text {clear }}=0$ at $15-16 \mathrm{~km}$ (372 $\mathrm{K}$ in potential temperature) is several kilometers and nearly $30 \mathrm{~K}$ above the LRM at $10-12 \mathrm{~km}$ and $345 \mathrm{~K}$. A convective cloud would have to detrain roughly $5 \mathrm{~km}$ above the LRM in order for the air within the outflow to reach the level of $Q_{\text {clear }}=0$ and eventually enter the stratosphere.

\section{Discussion}

The TTL is a region of transition between tropospheric stability dominated by deep convection, and stratospheric stability caused by ozone heating. Convenient boundaries for this layer are the lapse rate minimum (LRM) at $10-12 \mathrm{~km} \quad(340-350 \mathrm{~K}$ in isentropic coordinates), and the cold point tropopause (CPT) at $16-17 \mathrm{~km}(380-390 \mathrm{~K})$. Both of these values are readily calculated from temperature soundings. The location of these levels is indicated schematically in Fig. 11. Important zonal variations in the depth of the TTL are also present, and these are noted schematically in Fig. 11.

The TTL thus defined is related to ozone and convection in the region. The altitude of the 


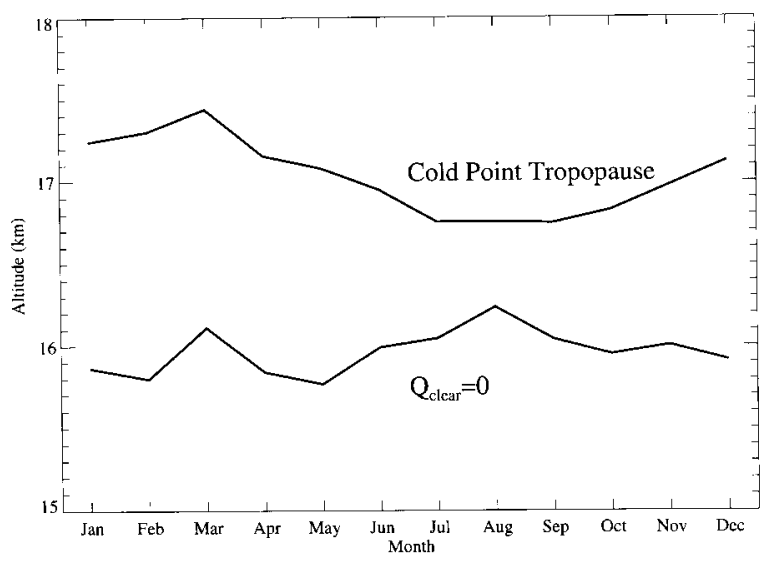

Fig. 10. Altitude of tropically averaged zero clear sky radiative heating $\left(Q_{\text {clear }}=0\right)$ estimated using a detailed radiative model (see text) with a monthly mean climatology, and the monthly mean cold point tropopause from this climatology.

lapse rate minimum at $10-12 \mathrm{~km}$ corresponds to a level generally just below the minimum in ozone in the upper troposphere. The mean position of the LRM also corresponds to the main influence of convection in the upper troposphere as observed from satellite cloud ob- servations and divergence of the wind field. The variations of the LRM level are also significantly correlated with convective activity.

In contrast, we find that convective activity is not strongly correlated with the cold point, the altitude of which varies coherently with the annual cycle of the stratospheric wave driven circulation (Yulaeva et al. 1994). The cold point is actually lower over some convective regions (Seidel et al. 2001), as illustrated in Fig. 11. The spatial distribution of cold point temperatures is likely a combination of several factors related to convection, including a direct cooling effect from mixing low- $\theta$ air from deep convection, an indirect dynamic response to the release of latent heat in convection at lower levels (Highwood and Hoskins 1998), and the radiative cooling associated with the presence of a thick cloud deck below the cold point (Gage et al. 1991; Norton 2001). The TTL has a lower boundary dominated by tropospheric processes (convection) and an upper boundary dominated by stratospheric radiative heating and a remote response to convection.

This analysis does not imply that convection is not important above the level of the LRM. As shown by Sherwood and Dessler (2001), even a small fraction of convection can have a significant effect on water vapor and ozone in the

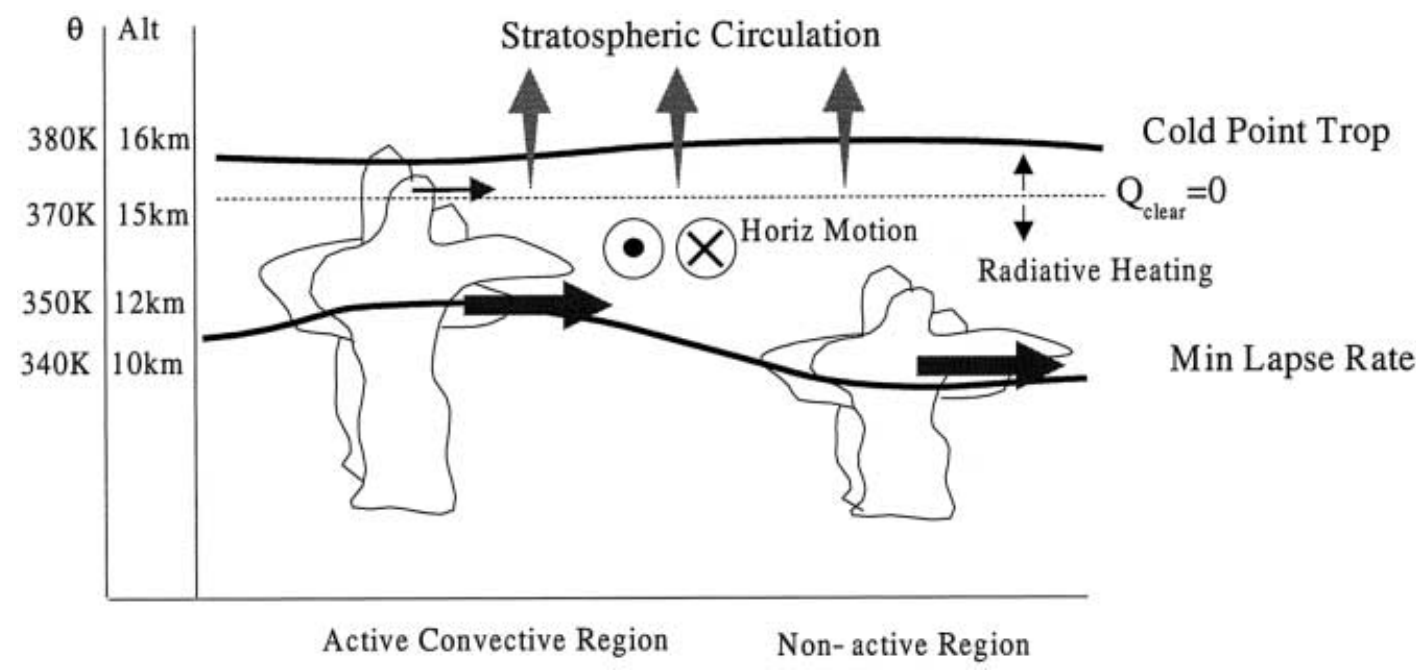

Fig. 11. Schematic Figure of the Tropical Tropopause Layer as discussed in the text. Altitude of Cold Point Tropopause and Minimum Lapse Rate, and $Q_{\text {clear }}=0$ shown. Horizontal motion indicated as vectors in and out of the page (it also occurs along the zonal dimension). Thin black arrows are radiative heating, large grey arrows are the stratospheric (Brewer-Dobson) circulation. Horizontal arrows are the detrainment from convection. 
tropopause region. A small fraction of the time (less than $0.5 \%$ ), convection does penetrate through the tropopause layer (Gettelman et al. 2002), as indicated in Fig. 11. In addition, we do not consider here the effect of horizontal (quasi-isentropic) motions within the TTL or between the TTL and the extratropical lower stratosphere. These motions, which have a preferential locations in space and time (Waugh and Polvani 2000), are likely to be important for determining the distribution of trace species in the TTL.

The LRM at $10-12 \mathrm{~km}(350 \mathrm{~K})$ is well below the level at which the clear sky radiative heating changes from negative to positive $(16 \mathrm{~km}$ or $370 \mathrm{~K})$. This implies that the main convective detrainment does not reach a level from which it can rise into the stratosphere. Deeper convection, which reaches within $1 \mathrm{~km}$ of the CPT or higher, is necessary to loft air to altitudes where it can reach the stratosphere.

There are coherent variations over the year in the altitude and depth of the tropical tropopause layer. Over the Western Pacific, the main convective outflow level is higher (and at higher potential temperature) than over the Eastern Pacific. Variations over the seasons follow the motion of convection. However, the CPT has a single and coherent annual cycle throughout the tropics (Seidel et al. 2001). Zonal variations of the level of the LRM are around $1 \mathrm{~km}$, and the LRM is lower in non-convective regions, shown schematically in Fig. 11. The level of the LRM is at lower potential temperatures in the subtropics. These regional variations in depth of layer may be significant for short lived species. In some regions short lived species will be exported into the TTL at higher altitudes than in other regions. Recognizing that isentropic motion within the TTL subsequent to convection will rapidly transport parcels horizontally, and that below $16 \mathrm{~km}$ parcels are subsiding, this implies that entrainment of TTL air into convection is necessary to move parcels in the TTL upward to within $1 \mathrm{~km}$ of the tropopause. This may have implications for the transport of, for example, the products of biomass burning into the TTL, because the burning generally occurs in dry seasons, when convection is not present (though sometimes the fires may themselves cause convection). Analysis of chemical budgets in the TTL (of carbon monoxide for ex- ample), might shed some light on this hypothesis that efficient transport into the TTL requires active convection.

Variations of the tropopause layer on interannual time scales have also been diagnosed. There is a strong signal of the El-Niño Southern Oscillation, which has a strong affect on the organization of convection and on the height of the LRM, particularly in the Pacific. Over the last 40 years, the cold point tropopause has risen $200-400 \mathrm{~m}$, consistent with previous work (Seidel et al. 2001). The altitude of the LRM is also rising at a similar rate, though the variability is higher at this level, so trends are not as significant. These trends appear consistent with increasing surface temperatures over the last 40 years, assuming that tropospheric lapse rates have remained fixed. We may hypothesize that the TTL may continue to rise if the warming expected from increased greenhouse gases is realized. Such a change is consistent with the sensitivity experiments of Thuburn and Craig (2002) which showed little sensitivity in a radiative-convective model to expected anthropogenic changes in carbon dioxide, because their surface temperatures remained fixed.

The analysis allows us to refine the schematics of the tropical tropopause layer recently presented by Highwood and Hoskins (1998), Folkins et al. (1999), Sherwood and Dessler (2001) and Vömel et al. (2002). Figure 11 indicates some of the important findings of this paper. The TTL can be defined as the region between the lapse rate minimum and the cold point. It has a varying thickness changing with convective activity, and is narrower with a higher base near active convective regions. The level of zero clear sky radiative heating is quite close to the tropopause.

Two of the major issues not addressed in this study are the impact of horizontal transport, and the related issue of linkages between the tropical TTL and the extratropical tropopause, which is located at $10-12 \mathrm{~km}$, nearly coincident with the base of the TTL. This horizontal motion is also indicated by vectors in Fig. 11. While the temperature structure may not be directly affected by such isentropic motion, the distribution of trace species like water vapor and ozone (and hence the radiative heating) may be affected. A future picture of the tropical 
tropopause layer would need to consider the role of the subtropics and the extratropics.

\section{Acknowledgments}

We would like to thank A.E. Dessler and S.C. Sherwood for advice and assistance with accessing data. Thanks to J. Witte for assistance with the SHADOZ archive. We also thank J. Thuburn, H. Vömel and I. Folkins for providing preprints of their work. This work also benefitted from numerous discussions with $\mathrm{S}$. Massie, L. Pan and W.J. Randel, and from the care of two anonymous reviewers.

\section{References}

Atticks, M.G. and G.D. Robinson, 1983: Some features of the structure of the tropical tropopause. Quart. J. Roy. Meteor. Soc., 109(460), 295-308.

Bjerknes, J. and E. Palmén, 1937: Investigations of selected european cyclones by means of serial ascents. Geofysiske Publikasjoner, 12(2).

Brewer, A.W., 1949: Evidence for a world circulation provided by the measurements of helium and water vapor distribution in the stratosphere. Quart. J. Roy. Meteor. Soc., 75, 351-363.

Christidis, N., M.D. Hurley, S. Pinnock, K.P. Shine, and T.J. Wallington, 1997: Further calculations of the radiative forcing of $\mathrm{CFC}-11$ and possible fluorocarbon replacements to the CFCs. J. Geophys. Res., 102, 19597-19609.

Eskridge, R.E., O.A. Alduchov, I.V. Chernykh, Z. Panmao, A.C. Polansky, and S.R. Dotty, 1995: A comprehensive aerological reference data set (CARDS): Rough and systematic errors. Bull. Amer. Meteor. Soc., 76, 1759-1775.

Folkins, I., 2002: Origin of lapse rate changes in the upper tropical troposphere. J. Atmos. Sci., 59, 992-1005.

, M. Loewenstein, J. Podolske, S.J. Oltmans, and M. Proffitt, 1999: A barrier to vertical mixing at $14 \mathrm{~km}$ in the tropics: Evidence from ozonesondes and aircraft measurements. $J$. Geophys. Res., 104(D18), 22095-22102.

Forster, P.M. de F. and K.P. Shine, 1997: Radiative forcing and temperature trends from stratospheric ozone depletion. J. Geophys. Res., 102, 10841-10855.

Gage, K.S., J.R. McAfee, D.A. Carter, W.L. Exklund, A.C. Riddle, G.C. Reid, and B.B. Balsley, 1991: Long-term mean vertical motion over the tropical pacific: Wind-profiling doppler radar measurements. Science, 254, 1771-1773. Reverse walker circulation.
Gettelman, A., M.L. Salby, and F. Sassi, 2002: The distribution and influence of convection in the tropical tropopause region. in press. J. Geophys. Res..

Highwood, E.J. and B.J. Hoskins, 1998: The tropical tropopause. Quart. J. Roy. Meteor. Soc., 124(549), 1579-1604.

Holton, J.R., P.H. Haynes, A.R. Douglass, R.B. Rood, and L. Pfister, 1995: Stratosphere-troposphere exchange. Rev. Geophys., 33(4), 403-439.

Kley, D., E.J. Stone, W.R. Henderson, J.W. Drummond, W.J. Harrop, A.L. Schmeltekopf, T.L. Thompson, and R.H. Winkler, 1979: In situ measurements of the mixing ratio of water vapor in the stratosphere. J. Atmos. Sci., 36, 2513-2524.

Kochanski, A., 1955: Cross sections of the mean zonal flow and temperature along $80 \mathrm{~W}$. J. Meteorology, 12(2), 95-106.

Manabe, S. and R.T. Wetherald, 1967: Thermal equilibrium of the atmosphere with a given distribution of relative humidity. J. Atmos. Sci., 24(3), 241-259.

Norton, W.A., 2001: Longwave heating of the tropical lower stratosphere. Geophys. Res. Lett., 28, 3653-3656.

Palmén, E. and C.W. Newton, 1969: Atmospheric Circulation Systems, vol. 13 of International Geophysics Series, Academic Press.

Peixoto, J.P. and A.H. Oort, 1992: Physics of Climate, American Institute of Physics, New York, NY.

Salby, M.L., H.H. Hendon, K. Woodberry, and K. Tanaka, 1991: Analysis of global cloud imagery from multiple satellites. Bull. Amer. Meteor. Soc., 72(4), 467-480.

Santer, B., T.M.L. Wigley, J. Boyle, D. Gaffen, J. Hnilo, D. Nychka, D. Parker, and K. Taylor, 2000: Statistical significance of trend differences in layer-average temperature time series. J. Geophys. Res., 105(D6), 73377356.

Seidel, D.J., R.J. Ross, J.K. Angell, and G.C. Reid, 2001: Climatological characteristics of the tropical tropopause as revealed by radiosondes. J. Geophys. Res., 106, 7857-7878.

Shapiro, M.A., 1980: Turbulent mixing within tropopause folds as a mechanism for the exchange of chemical constituents between the stratosphere and the troposphere. J. Atmos. Sci., 37, 994-1004.

Sherwood, S.C. and A.E. Dessler, 2001: A model for transport across the tropical tropopause. $J$. Atmos. Sci., 58, 765-779.

Thompson, A.M. and J.C. Witte, 1999: SHADOZ (Southern Hemisphere ADditional OZonesondes): A new data set for the earth science community. Earth Observer, 11(4), 27-30. 
Thuburn, J. and G.C. Craig, 2002: On the temperature structure of the tropical substratosphere. submitted to J. Geophys. Res. .

Vömel, H., S.J. Oltmans, B.J. Johnson, F. Hasebe, M. Shiotani, M. Fujiwara, N. Nishi, M. Agama, J. Cornejo, F. Paredes, and H. Enriquez, 2002: Balloon-borne observations of water vapor and ozone in the tropical upper troposphere and lower stratosphere. in press. J. Geophys. Res..
Waugh, D.W. and L.M. Polvani, 2000: Climatology of intrusions into the tropical upper troposphere. Geophys. Res. Lett., 27(23), 3857-3860.

Willett, H.C., 1944: Descriptive Meterology, Academic Press, New York, 48.

Yulaeva, E., J.R. Holton, and J.M. Wallace, 1994: On the cause of the annual cycle in tropical lowerstratospheric temperatures. J. Atmos. Sci., 51(2), 169-174. 